University of Nebraska - Lincoln

DigitalCommons@University of Nebraska - Lincoln

$5-1-1990$

\title{
Magnetic and structural studies in Sm-Fe-Ti magnets
}

\author{
Y. Wang \\ Department of Physics, Kansas State University, Manhattan, Kansas
}

George C. Hadjipanayis

Kansas State University, hadji@udel.edu

A. Kim

Crucible Research, Pittsburgh, Pennsylvania

N.C. Liu

Crucible Research, Pittsburgh, Pennsylvania

David J. Sellmyer

University of Nebraska-Lincoln, dsellmyer@unl.edu

Follow this and additional works at: https://digitalcommons.unl.edu/physicssellmyer

Part of the Physics Commons

Wang, Y.; Hadjipanayis, George C.; Kim, A.; Liu, N.C.; and Sellmyer, David J., "Magnetic and structural studies in Sm-Fe-Ti magnets" (1990). David Sellmyer Publications. 126.

https://digitalcommons.unl.edu/physicssellmyer/126

This Article is brought to you for free and open access by the Research Papers in Physics and Astronomy at DigitalCommons@University of Nebraska - Lincoln. It has been accepted for inclusion in David Sellmyer Publications by an authorized administrator of DigitalCommons@University of Nebraska - Lincoln. 


\section{Magnetic and strucural studies in Sm-Fe-Ti magnets}

Y. Wang and G. C. Hadjipanayis ${ }^{\text {a) }}$

Depariment of Physics, Rarsass State University, Manhattan, Kansas 66506

A. Kim and N.C. Liu

Crucible Research, Pitsburgh, Pennsyluania 15200

D. J. Sellmyer

Department of Physics and Astronomy, University of Nebraska, Lincoln. Nebraska 68588-0111

The effects of vanadium substitution on the magnetic properties of Sm-Fe-Ti-V melt-spun ribbons and the magnetic properties and microstructure of sintered $\mathrm{Sm}-\mathrm{Fe}$-Ti based magnets are reported. The highest coercivity, $H_{c}=10.65 \mathrm{kOe}$, was obtained in a heat-treated melt-spun $\mathrm{Sm}_{8} \mathrm{Fe}_{75.5} \mathrm{Ga}_{0.5} \mathrm{Ti}_{8} \mathrm{~V}_{8}$ alloy. This is the highest value of the coercivities reported in alloys with the $\mathrm{ThMN}_{12}$-type structure. Bulk magnets were prepared by the usual powder metallurgy technique. However, their highest coercivity $(\sim 2 \mathrm{kOe})$ was much less than that of the corresponding ribbons. The low coercivity of sintered magnets has been attributed to their nonuniform microstructure.

\section{INTRODUCTION}

The discovery of $\mathrm{Nd}-\mathrm{Fe}-\mathrm{B}$ magnets ${ }^{8,2}$ having excellent hard magnetic properties has stimulated search for new ternary rare-earth-iron based compounds. Several ternary compounds with composition $\mathrm{SmFe}_{12-x} \mathrm{Ti}$ based on the $\mathrm{ThMn}_{12}$-type structure, where $\mathrm{T}=\mathrm{Ti}, \mathrm{V}, \mathrm{Cr}, \mathrm{Mo}, \mathrm{W}$ or Si and $x=1.2$ or 2 , have been found to have a relatively high anisotropy, saturation magnetization, and Curie temperature $^{3-5}$ that make them good candidates for permanent magnet development. Recently, high coercivities have been obtained in ribbon samples, ${ }^{6-8}$ with a maximum value of 9.8 $\mathrm{kOe}^{8}{ }^{8}$ Based on the reported high anisotropy field of these systems, there is still the possibility for obtaining higher coercivity by further substitutions in $\mathrm{Sm}-\mathrm{Fe}-\mathrm{Ti}-\mathrm{V}$ alloys. Very few reports exist on sintered $\mathrm{Sm}-\mathrm{Fe}$-Ti magnets. ${ }^{8}$ This is because it is difficult to obtain a high coercivity in sintered magnets.

In this paper we report the results of vanadium substitution on the magnetic properties of Sm-Fe-Ti-V melt-spun ribbons, and we present preliminary results of the magnetic properties and microstructure of sintered Sm-Fe-Ti-V magnets. This would hopefully help us understand the lack of magnetic hardening in bulk magnets.

\section{EXPERIMENT}

Several alloys with composition $\mathrm{Sm}_{8} \mathrm{Fe}_{76 \ldots y} \mathrm{M}_{y} \mathrm{Ti}_{8} \mathrm{~V}_{8}$ and $\mathrm{Sm}_{8} \mathrm{Fe}_{76} \mathrm{Ti}_{8-} \mathrm{M}_{z} \mathrm{~V}_{8}$, where $\mathrm{M}=\mathrm{Cr}, \mathrm{Mn}, \mathrm{Ga}, \mathrm{Zr}, \mathrm{Nb}$, $\mathrm{Mo}, \mathrm{W}$, and $0 \leqslant y, z \leqslant 2$ were prepared by arc-melting starting materials of $99.9 \%$ purity under argon atmosphere. Pieces of ingots were made into ribbons by the melt-spinning technique. Magnetic hardening was obtained in the ribbons by heat-treating the sampies at a temperature in the range 800 $850^{\circ} \mathrm{C}$ for times ranging from 5 to $150 \mathrm{~min}$. Sintered magnets were prepared using the usual powder metallurgy technique. ${ }^{2}$ It was necessary that an excess amount of $\mathrm{Sm}$ be incorporated into the alloy in order to compensate for the

a) Present address: Department of Physics and Astronomy, University of Delaware, Nowark, DE 19716. vaporization of Sm during alloying, sintering, and heat treato ing because $\mathrm{Sm}$ has a high vapor pressure. Magnetic properties were measured using a vibrating sample magnetometer (VSM) with applied fields of up to $17.7 \mathrm{kOe}$. The phases present were determined by $\mathrm{x}$-ray diffraction and thermomagnetic analysis. A Jeol $100 \mathrm{C}$ scanning transmission electron microscope (STEM) equipped with an energy dispersive $\mathrm{x}$-ray analyzer (EDXA) was used to study the grain structure of the sintered magnets.

\section{RESULTS ANO DISCUSSION}

\section{A. Kelt-spun magnets}

In a previous paper ${ }^{10}$ we showed that crystallized SmFe-Ti ribbons have the $\mathrm{ThMn}_{12}$-type structure when annealed above $800^{\circ} \mathrm{C}$, but for lower annealing temperatures some alloys have the $\mathrm{TbCu}_{7}$-type structure. The higher annealing temperatures also were used in this study to obtain a high coercivity. Samples annealed at $800^{\circ} \mathrm{C}$ exhibit a higher coercivity than at $850^{\circ} \mathrm{C}$. However, longer times are needed at the lower annealing temperatures to achieve the optimum

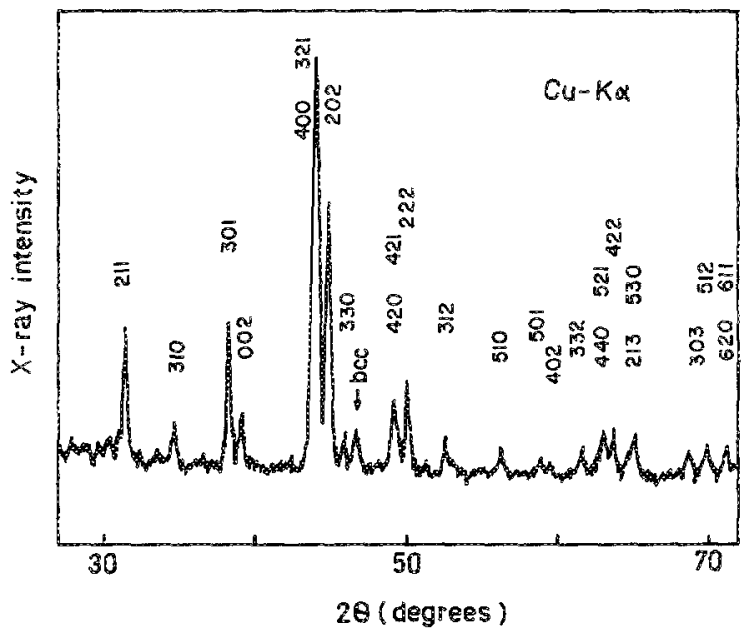

FIG. 1. X-ray diagram of $\mathrm{Sm}_{8} \mathrm{Fe}_{76} \mathrm{Ti}_{8} \mathrm{~V}_{8}$ ribbons heated at $800^{\circ} \mathrm{C}$ for 60 min. 
TABLE I. Magnetic properties of Sm-Fe-Ti based ribbons annealed at $800^{\circ} \mathrm{C}$.

\begin{tabular}{ccc}
\hline Composition & $\begin{array}{c}H_{c} \\
(\mathrm{kOe})\end{array}$ & $\begin{array}{c}M_{s} \\
(\mathrm{G})\end{array}$ \\
\hline $\mathrm{Sm}_{8} \mathrm{Fe}_{83} \mathrm{Ti}_{\mathrm{i}_{9}}$ & 5.6 & 806 \\
$\mathrm{Sm}_{8} \mathrm{Fe}_{76} \mathrm{Ti}_{8} \mathrm{~V}_{8}$ & 10.2 & 664 \\
$\mathrm{Sm}_{8} \mathrm{Fe}_{76} \mathrm{Ti}_{7} \mathrm{ZE}_{1} \mathrm{~V}_{8}$ & 10.25 & 674 \\
$\mathrm{Sm}_{8} \mathrm{Fe}_{76} \mathrm{Ti}_{6} \mathrm{Zr}_{2} \mathrm{~V}_{8}$ & 9.4 & $\ldots$ \\
$\mathrm{Sm}_{8} \mathrm{Fe}_{76} \mathrm{Ti}_{7} \mathrm{Nb}_{1} \mathrm{~V}_{8}$ & 9.4 & 608 \\
$\mathrm{Sm}_{8} \mathrm{Fe}_{76} \mathrm{Ti}_{7} \mathrm{Mo}_{1} \mathrm{~V}_{8}$ & 8.1 & 596 \\
$\mathrm{Sm}_{8} \mathrm{Fe}_{76} \mathrm{Ti}_{7} \mathrm{~W}_{1} \mathrm{~V}_{8}$ & 8.0 & 599 \\
$\mathrm{Sm}_{8} \mathrm{Fe}_{75.5} \mathrm{Ga}_{0.5} \mathrm{Ti}_{8} \mathrm{~V}_{8}$ & 10.65 & 692 \\
\hline
\end{tabular}

coercivity. The $x$-ray diffraction pattern of $\mathrm{Sm}_{8} \mathrm{Fe}_{76} \mathrm{Ti}_{8} \mathrm{~V}_{8}$ ribbons annealed at $800^{\circ} \mathrm{C}$ for $60 \mathrm{~min}$ is shown in Fig. 1. Nearly all peaks could be indexed with the $\mathrm{ThMn}_{12}$ structure except one peak which comes from a secondary bcc phase with a lattice constant close to $\alpha-\mathrm{Fe}$. In an attempt to obtain higher coercivities several substitutions have been carried out on $\mathrm{Sm}-\mathrm{Fe}-\mathrm{Ti}-\mathrm{V}$ alloys. Samples with composition $\mathrm{Sm}_{8} \mathrm{Fe}_{76 \ldots} \mathrm{Ti}_{8} \mathrm{M}_{9} \mathrm{Ti}_{8} \mathrm{~V}_{8}$ and $\mathrm{Sm}_{8} \mathrm{Fe}_{76} \mathrm{Ti}_{8-2} \mathrm{M}_{2} \mathrm{~V}_{8}$ where $\mathrm{M}=\mathrm{Cr}, \mathrm{Mn}, \mathrm{Ga}, \mathrm{Zr}, \mathrm{No}, \mathrm{Mo}, \mathrm{W}$, and $\mathrm{O} \leqslant y, z \leqslant 2$ were made. Table I shows the coercivity and saturation magnetization $M_{\mathrm{s}}$, for $\mathrm{Sm}-\mathrm{Fe}-\mathrm{Ti}-\mathrm{V}$ ribbons annealed at $800^{\circ} \mathrm{C}$ for $60 \mathrm{~min}$. The magnetic data show that an increase in coercivity can be obtained by replacing $\mathrm{Fe}$ with a small amount of $\mathrm{Ga}$ or by replacing $\mathrm{Ti}$ with a small amount of $\mathrm{Z}$. Annealed $\mathrm{Sm}_{8} \mathrm{Fe}_{76}$ $\mathrm{Ti}_{7} \mathrm{Zr}_{1} \mathrm{~V}_{8}$ and $\mathrm{Sm}_{8} \mathrm{Fe}_{75.5} \mathrm{Ga}_{0.5} \mathrm{Ti}_{8} \mathrm{~V}_{8}$ ribbons have a coercivity of 10.25 and $10.65 \mathrm{kOe}$, respectively. To our knowledge, these are the highest values among all the reported values of coercivity in melt-spun ribbons with the $\mathrm{ThMn}_{12}$-type structure. A typical magnetic hysteresis loop for these samples is shown in Fig. 2.

\section{Sintered magnets}

Alloys with composition $\mathrm{Sm}_{9} \mathrm{Fe}_{83} \mathrm{Ti}_{8}$ and $\mathrm{Sm}_{8} \mathrm{Fe}_{76} \mathrm{Ti}_{8} \mathrm{~V}_{8}$ were sintered at $1100^{\circ} \mathrm{C}$ for $60 \mathrm{~min}$ and quenched in argon

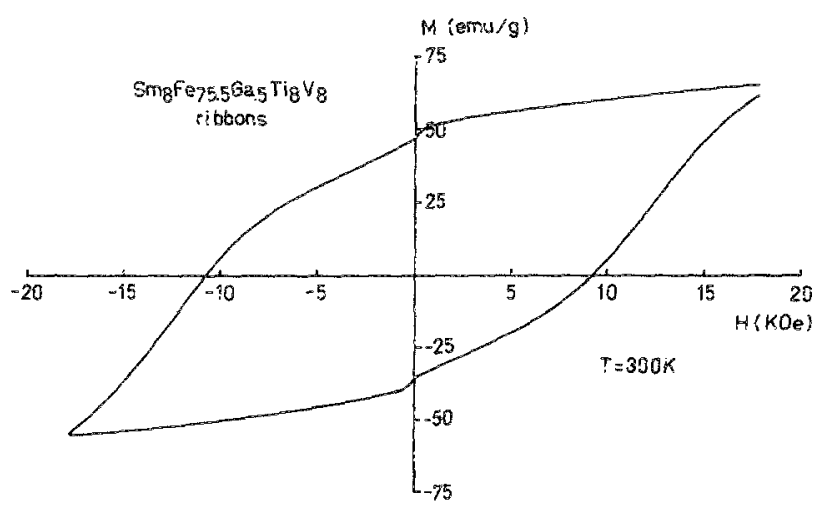

FIG. 2. Magnetic hysteresis loop of $\mathrm{Sm}_{8} \mathrm{Fe}_{75.5} \mathrm{Ga}_{0.5} \mathrm{Ti}_{8} \mathrm{~V}_{8}$ ribbons annealed at $800^{\circ} \mathrm{C}$ for $60 \mathrm{~min}$

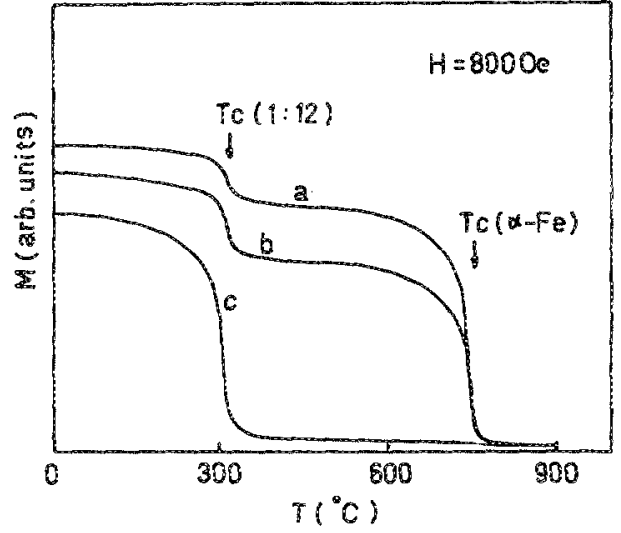

FIG. 3. Thermomagnetic data of $5 \mathrm{~m}_{9} \mathrm{Fe}_{83} \mathrm{Ti}_{8}$ magnets sintered in (a) vacuun, (b) argon gas, and (c) Sm atmosphere.

gas, and then were annealed at $730^{\circ} \mathrm{C}$ for $40 \mathrm{~min}$. Thermomagnetic data of sintered $\mathrm{Sm}_{9} \mathrm{Fe}_{83} \mathrm{Ti}_{8}$ magnets under various sintering conditions are shown in Fig. 3. Samples sintered in Sm atmosphere appear to have nearly a single phase with the ThMn $n_{12}$-type structure. But the $1: 12$ phase is a minority phase in the other two samples where $\alpha$-Fe is predominant. This result is attributed to the large Sm losses during sintering which make it difficult for the $1: 12$ phase to be formed.

Figure 4 shows the magnetic hysteresis loops of $\mathrm{Sm}_{9} \mathrm{Fe}_{83} \mathrm{Ti}_{8}$ and $\mathrm{Sm}_{8} \mathrm{Fe}_{76} \mathrm{Ti}_{8} \mathrm{~V}_{8}$ magnets sintered in Sm atmosphere. The former magnets have a coercivity of only 800 Oe, while the latter have a coercivity of about $2 \mathrm{kOe}$. These values are far less than those of the corresponding ribbons, ${ }^{3,8}$ which are 5.6 and $9.8 \mathrm{kOe}$, respectively. The large differences are attributed to the different microstructure of the two magnets. The microstructure of ribbons consists 9 of fine $1: 12$ grains with a size in the range of $300-800 \AA$. On the contrary the grain structure of the sintered magnets is not well developed [Fig. 5(a)]. The grains are not well-defined polygons like in other sintered magnets. The Sm-Fe-Ti-V

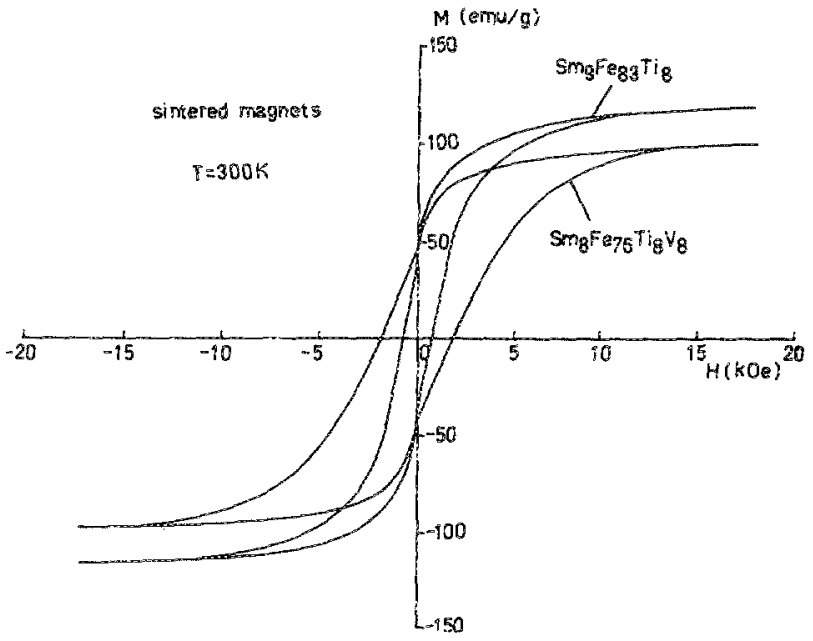

FIG. 4. Magnetic hysteresis loops of sintered $\mathrm{Sm}_{8} \mathrm{Fe}_{83} \mathrm{Tl}$, and $\mathrm{Sm}_{8} \mathrm{Fe}_{76} \mathrm{Ti}_{8} \mathrm{~V}_{8}$ magnets. 

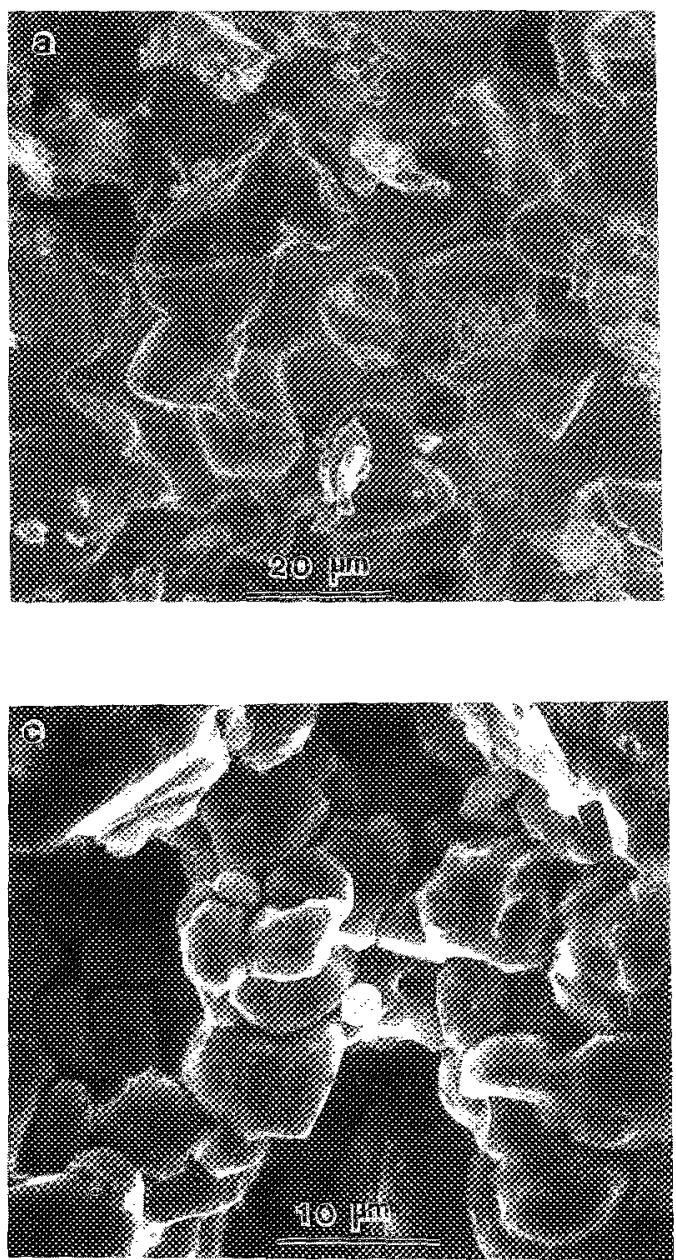

FIG. 5. SEM studies showing the grain structure of (a) $\mathrm{Sm}_{9} \mathrm{Fe}_{83} \mathrm{Ti}_{8}$ and (c) $\mathrm{Sm}_{\mathrm{g}} \mathrm{Fe}_{76} \mathrm{Ti}_{8} \mathrm{~V}_{8}$ magnets.

magnet with the highest coercivity appeared to have a more uniform microstructure [Fig. 5(b)]. All sintered magnets were found to contain at least four phases (Fig. 6); the 1:12 phase, $\alpha$-Fe, a Sm-rich-Fe-Ti phase and another Sm-rich phase possibiy a samarium oxide. In the magnets with a nearly single $1: 12$ phase, the $1: 12$ grains had a size in the range of $8-15 \mu \mathrm{m}$. Additions of extra samarium were found to lead to Sm-rich regions near the grain boundaries or to Sm-rich grains squeezed between the 1:12 grains.

\section{CONCLUSIONS}

Coercivities exceeding 10 kOe have been obtained in melt-spun Sm-Fe-Ti-V based magnets with the highest value of 10.65 kOe observed in $\mathrm{Sm}_{8} \mathrm{Fe}_{75.5} \mathrm{Ga}_{0.5} \mathrm{~T}_{18} \mathrm{~V}_{8}$. Sintered magnets with similar composition have been prepared into a nearly single 1.12 phase but their maximum coercivity was only $2 \mathrm{kOe}$. The much smaller coercivity of sintered magnets has been attributed to their microstructure which is not well developed for optimum magnetic hardening.
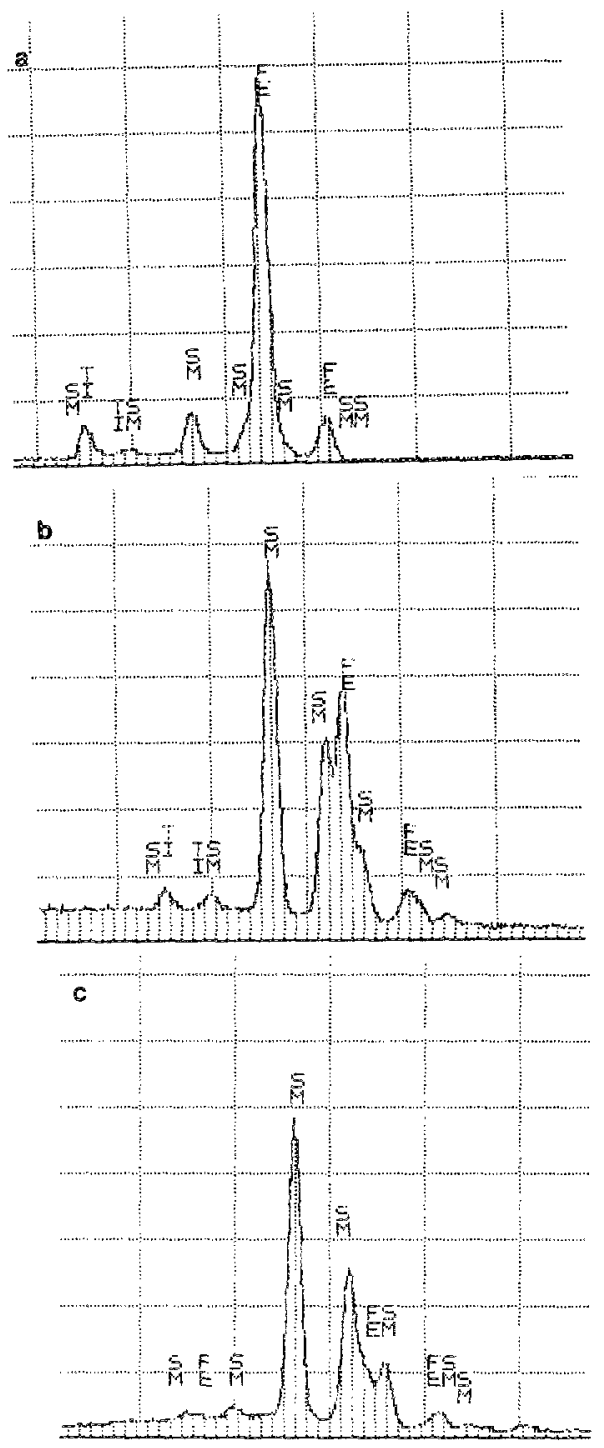

FIG. 6. EDXA studies in $S m-F e-T i=V$ magnets showing the composition of the various phases: (a) 1:12, (b) Sm-rich-Fe-Ti, (c) Sm-rich.

\section{ACKNOWLEOMENT}

This work was supported by the U.S. Department of Energy Contract No. DE-FG02-86ER45263 and DEFG02-86ER45262.

'G. C. Hadjipanayis, R. C. Hazelton, and K. R. Lawless, Appl. Phys. Lett. 43, 797 (1983).

${ }^{2}$ M. Sagawa, F. Fujimura, N. Togawa, H. Yamanota, and Y. Matsuura, J. Appl. Phys. 55, 2083 (1984).

${ }^{3} \mathbf{K}$. Ohashi, Y. Tawara, R. Osugi, and M. Shimao, IEEE Trans. Magn. MAG-23, 3101 (1987).

${ }^{4}$ K. H. J. Buschow, J. Appl. Phys. 63, 3130 (1988).

'J. V. Uu, T. Wang, S. G. Zhang, Y. Z. Wang, and Z. X. Wang, J. Magn. Magn. Mater. 74, 22 (1988)

${ }^{6} \mathrm{E}$. W. Singleton, J. Strzeszewski, G. C. Hadjipanayis, and D. J. Sellmyer, J. Appl. Phys. 64, 5717 (1988)

${ }^{7} \mathrm{~F}$. E. Pinkerton and D. J. VanWingerden, Intermag, Washington, DC, 1989.

R. Yamagishi, M. Okada, and M. Homma, Mater. Trans. JIM 30, (1988). ${ }^{4}$ J. Strzewzewski, Y. Z. Wang, E. W. Singleton, and G. C. Hadjipanayis, Intermag, Washington, DC, 1989. 